\title{
Knowledge, Attitude and Behavior regarding Antibiotics Misuse and Use among Medical Students of Public Sector Medical College of Faisalabad
}

\author{
Mehr Muhammad Adeel Riaz, ${ }^{1}$ Rameen Shahid, ${ }^{2}$ Areeba Naeem, ${ }^{3}$ Sumera Badar Ehsan, ${ }^{4}$ Sajjad Ali, ${ }^{5}$ Mariam Saleem ${ }^{6}$ \\ 1,2,3Final Year MBBS Student, Punjab Medical College, Faisalabad-Pakistan, ${ }^{4}$ Department of Medical Education, Faisalabad Medical University, Faisalabad-Pakistan, ${ }^{5}$ Department of \\ Medicine, Continental Medical College, Lahore Pakistan, ${ }^{6}$ Medical Officer, National Hospital, Faisalabad Pakistan
}

\begin{abstract}
Background: Antibiotic resistance is a critical issue that needs to be addressed, especially in a developing country like Pakistan. Overuse of antibiotics has rendered life-saving drugs ineffectual, creating a major dilemma for local hospitals. Objective: To assess and evaluate the knowledge, attitude and behavior regarding antibiotics misuse among medical students. Study Design: An Observational descriptive study. Settings: The medical students of public sector medical college of Faisalabad Pakistan. Duration: After getting approval of the ethical committee, the duration of study was 5 weeks. Methodology: 200 students were interviewed according to the pattern of the questionnaire. Results: $82 \%$ of students were most likely to use antibiotics during common viral infections. However, $88.5 \%$ knew about the consequences of antibiotics misuse i.e. antibiotic resistance, but still $53.50 \%$ sought non-prescribed antibiotics from medical stores and $60.5 \%$ of them didn't complete the antibiotics course recommended by their doctors. $40.50 \%$ of students admitted to self-medicate themselves on antibiotics twice a year. Conclusion: Efforts are necessary to persuade the health education programs to inform the general public and health care workers about the long-term hazards of antibiotic resistance.
\end{abstract}

Keywords: Antibiotics resistance, Non-prescribed antibiotics, Per annum usage.

Corresponding Author Submitted for Publication: 04-10-2019 Accepted for Publication: 11-03-2020

Dr. Mehr Muhammad Adeel Riaz, Final Year MBBS Student, Punjab Medical College, Faisalabad-Pakistan. Email: adeelriaz369@gmail.com

Citation: Riaz MMA, Shahid R, Naeem A, Ehsan SB, Ali S, Saleem M. Knowledge, Attitude and Behavior regarding Antibiotics Misuse and Use among Medical Students. APMC 2020;14(2):164-7.

DOI: 10.29054/APMC/2020.718

\section{INTRODUCTION}

The discovery of antibiotics revolutionized the concept of modern medicine. Antibiotics which are defined as, "chemical substance produced by a living organism, generally a microorganism, that is detrimental to other microorganisms ${ }^{1}$ are the most commonly sold drugs in the developing countries ${ }^{2}$ Misuse can be defined as to use (something) incorrectly. ${ }^{3}$ Over the counter availability and usage of the antibiotics pose a serious threat to the global population. The irrational prescription of antibiotics, lack of the concerns about long term drug resistance and consequence versus treating current symptoms by healthcare providers and poor health policies concerning medical usage of life saving drugs like antibiotics are the major contributing factors in putting a strain on the long term efficacy of the drug. ${ }^{4}$ There are multiple layer to this phenomenon which is leading to unwanted adverse effects that leave the patient or a user in an unexpected situation e.g. antibiotics resistance bacterial strains (super-bugs), treatment failure, toxicity, prolonged treatment time, hospital stay and increased cost; ${ }^{5}$ eventually putting economic burden on national health system. ${ }^{6}$

It has been approximated that by 2050, an increase in drug resistance infections would cost nearly 10 million lives per year and 100 trillion US dollars of the economy would be at stake. ${ }^{7}$ According to the report published by the World Health Organization (WHO) in 2014, antibiotic misuse was the cause of severe treatment failures in developed countries like
Australia, UK, Canada, Japan, Austria, Norway, France and South Africa. A 2014 report by the World Health Organization (WHO) states that there were about 480,000 cases of drug resistance because of antibiotic misuse. ${ }^{8}$ Drawing Asia into the picture, reports present the data of fully drug resistant population percentage like this i.e. $2.2 \%$ in China, $0.3 \%$ in South Korea drug resistant cases out of the total cases presented to the hospitals. Furthermore, the multi-drug resistance phenomenon was observed in $59.3 \%$ of the population of Asian countries. ${ }^{9}$ If we speculate this ratio in Pakistan, data suggest that $41 \%$ of the nation doesn't understand the idea of drug resistance so opt to use antibiotics without any hesitation. ${ }^{10}$ The purpose of conducting this study is to assess the level of knowledge, and misconceptions associated with attitude and behavior regarding the misuse of antibiotics among medical students i.e. future healthcare providers and iconic stakeholders involved in shaping the future of antibiotic prescription and eventually the community health.

\section{METHODOLOGY}

Study Design: This was an observational descriptive study. Settings: This research was conducted in the public sector medical college of Faisalabad Pakistan.

Duration: After acquiring approval of the ethical committee, the duration of study was 5 weeks.

Sample Size: 200 medical students $(n=200)$. 
Inclusion Criteria: All students [pre-clinical (1st and 2nd year) \& clinical (3rd, 4th and final year)] of MBBS of public sector medical college of Faisalabad were included.

Exclusion Criteria: All students of Dentistry, Allied health sciences and paramedics were excluded.

Methods: We used "Questionnaire" as our data collection tool that was designed to get information from 200 students, consisting of three blocks: knowledge, attitude and behavior.
Students were Informed and explained the structure, methodology and purpose of the research. Based on provided information, informed consent was obtained in the form of signatures on questionnaires from each recording their responses. Data analysis tool employed was SPSS version 21 and Microsoft data analyst software. The sample technique utilized was according to the non-probability convenience method.

\section{RESULTS}

The result section is based on three categories for which the knowledge, attitude and behavior of the medical students were evaluated. a- General knowledge of medical students (pre-clinical and clinical) about indications of antibiotics use. b- Effects of misuse: Unnecessary self-medication and usage of antibiotics without healthcare professional's prescription. (Shown in Table 1)

Table 1: Knowledge $(n=200)$

\begin{tabular}{|c|c|c|c|c|c|}
\hline Questions asked in questionnaire & Options & 1st prof. $\mathrm{n}(\%)$ & 2nd prof. $n(\%)$ & 3rd prof. $\mathrm{n}(\%)$ & Final prof. $\mathrm{n}(\%)$ \\
\hline \multirow{3}{*}{$\begin{array}{l}\text { 1. Overuse of antibiotics can cause } \\
\text { antibiotics resistance? }\end{array}$} & Yes & $41(20.5)$ & $46(23)$ & $44(22)$ & $46(23)$ \\
\hline & No & $5(2.5)$ & $2(1)$ & $3(1.5)$ & $4(2)$ \\
\hline & Not Sure & $4(2)$ & $2(1)$ & $3(1.5)$ & $0(0)$ \\
\hline \multirow{3}{*}{$\begin{array}{l}\text { 2. What do you think whether } \\
\text { antibiotics are used to treat viral } \\
\text { infections or not? }\end{array}$} & Yes & $45(22.5)$ & $38(19)$ & $44(22)$ & $37(18)$ \\
\hline & No & $3(1.5)$ & $4(2)$ & $4(2)$ & $13(6.5)$ \\
\hline & Not Sure & $2(1)$ & $8(4)$ & $2(1)$ & $0(0)$ \\
\hline \multirow{3}{*}{$\begin{array}{l}\text { 3. What you think whether } \\
\text { antibiotics are those medicines that } \\
\text { are prescribed in pain and fever? }\end{array}$} & Yes & $15(7.5)$ & $13(6.5)$ & $32(16)$ & $35(17.5)$ \\
\hline & No & $15(7.5)$ & $28(14)$ & $15(7.5)$ & $14(7)$ \\
\hline & Not Sure & $20(10)$ & $9(4.5)$ & $3(1.5)$ & $1(0.5)$ \\
\hline
\end{tabular}

Attitude of medical students regarding buying the OTC antibiotics from local pharmacies for common cold has been shown in Table 2.

Table 2: Attitude patterns seem among medical students ( $n=200)$ :

\begin{tabular}{|c|c|c|c|c|c|}
\hline Question asked in questionnaire & Options & 1st prof. $\mathbf{n}(\%)$ & 2nd prof. $\mathbf{n}(\%)$ & 3rd prof. $\mathbf{n}(\%)$ & Final prof. $\mathbf{n}(\%)$ \\
\hline \multirow{2}{*}{$\begin{array}{c}\text { 1. When you feel cold, do you seek non- } \\
\text { prescribed antibiotics from medical store? }\end{array}$} & Yes & $37(18.5)$ & $22(11)$ & $25(12.5)$ & $18(9)$ \\
\cline { 2 - 6 } & No & $11(5.5)$ & $20(10)$ & $24(12)$ & $29(14.5)$ \\
\cline { 2 - 6 } & Not Sure & $2(1)$ & $6(3)$ & $1(0.5)$ & $1(0.5)$ \\
\hline
\end{tabular}

In this section of questionnaire, student's behavior was evaluated about the completion of the antibiotics course.

Table 3: Behavioral patterns of medical students regarding usage of antibiotics: $(n=200)$

\begin{tabular}{|l|c|c|c|c|c|}
\hline Questions asked in questionnaire & Option & 1st prof. $\mathbf{n}(\%)$ & 2nd prof. $\mathbf{n}(\%)$ & 3rd prof. $\mathbf{n}(\%)$ & Final prof. $\mathbf{n}(\%)$ \\
\hline \multirow{2}{*}{$\begin{array}{l}\text { Whether you completed your full } \\
\text { course of antibiotics recommended by }\end{array}$} & Yes & 10 & 23 & 43 & 46 \\
\cline { 2 - 6 } & No & 31 & 20 & 5 & 4 \\
\cline { 2 - 6 } \\
doctor? & Not Sure & 4 & 7 & 2 & 0 \\
\hline
\end{tabular}

40

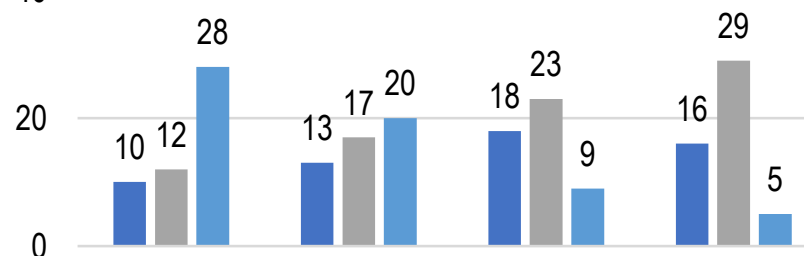

$$
\begin{aligned}
& \text { Final Prof. (n) 3rd Prof. (n) 2nd Prof. (n) 1st Prof. (n) } \\
& \text { Study Year } \\
& \text { - Once a Year } \quad \text { Twice A Year } \square \text { Not at All }
\end{aligned}
$$

Figure 1: How often you self-medicate yourselves on antibiotics per annum? How often you self-medicate yourselves on antibiotics per annum?

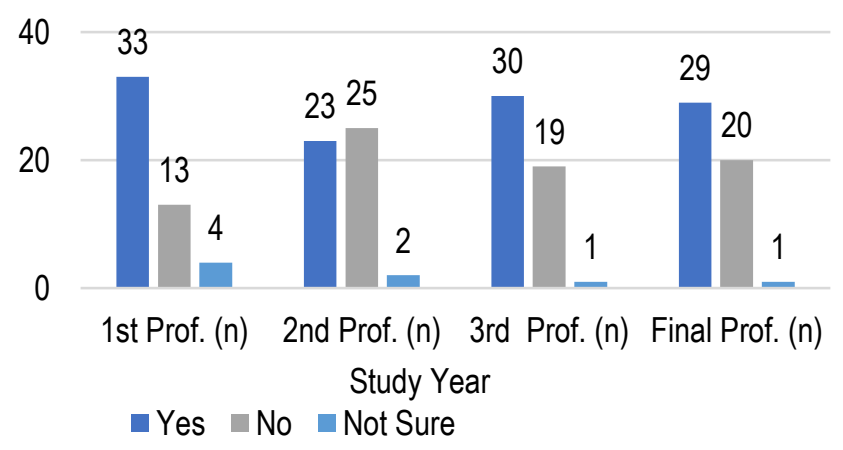

Figure 2: Have you ever shared antibiotics with someone in their friends and family with similar symptoms as yours 
Furthermore, students were asked how many times a year they seek antibiotics from local pharmacies without prescription of healthcare professionals. Data was compiled in graphical form as shown in Figure 1.

An interested pattern that was observed after data analysis that 33 students from $11^{\text {st }}$ professional compared to the 29 students from final professional agreed on sharing the leftover antibiotics with their family and friends; promoting the use of over the counter antibiotics. This problem highlights the ethical issues related to this particular problem. Figure 2 shows the comparison of data between each professional.

\section{DISCUSSION}

We live in a world where a host of information regarding disease signs, symptoms and management can be accessed with a few clicks or still worse unreliable ear to ear layman advisories. Over the counter usage of antibiotics and its aftereffects is a significant challenge that continues to threaten the health of our society at enormous scales, more so in recent years. It wouldn't be wrong to say that antibiotic resistance has itself become a health problem and ignorance can be blamed as the key actor in precipitating this issue. Especially in a country like Pakistan where broad-spectrum antibiotics can be effortlessly purchased from any local pharmacy without any prescription. ${ }^{11}$ Another factor mounting this problem is the lack of monitoring laws and policies relating to availability of antibiotics without any prescription. ${ }^{12}$

Knowledge of medical students regarding antibiotics misuse and use: Data analysis on student's general knowledge about the effects of antibiotics misuse suggests that $41 \%$ $(n=20.5)$ of students from pre-clinical professionals ( 1 st and $2 n d$ year) as compared to $68 \%(n=136)$ of students from clinical professionals (3rd, 4th and final year), were aware of the antibiotics resistance effects. Despite having a strong base of knowledge about misuse effects, students were continuously using antibiotics without any precaution. When the knowledge of medical students about this problem was evaluated, $22.5 \%$ $(n=45)$ of students from pre-clinical professionals and $59.5 \%$ $(n=119)$ from clinical professionals believed that antibiotics are used to treat viral infections instead of bacterial. This particularly highlights the most important reason for antibiotic misuse. The excessive use of antibiotics without knowing the underlying cause of infection, has caused an increase in resistance. As a result, low potency antibiotics will lose their effectiveness and will leave the patient in need of an extended antibiotics course. ${ }^{13}$ A similar study also established the presence of worse case scenarios and more expenditure on healthcare. ${ }^{14}$

The third major issue regarding their knowledge about antibiotics was that they confused the painkillers/analgesics with antibiotics. Around $7.5 \%(n=15)$ of students from pre-clinical professionals and $40 \%(n=80)$ from clinical professionals, believed that antibiotics are those medicines that are prescribed in pain, fever and general infections. An article suggesting the desensitization of the genome of bacteria against antibiotics when used for the treatment of the general infections; ${ }^{15}$ ultimately led to the failure of treatment culminating in increased antibiotics resistant cases in the future.

Attitude of medical students regarding antibiotic misuse and use: Concerning attitude, $18.5 \%(n=37)$ students from preclinical and $40 \%(n=80)$ from clinical professionals agreed to seek non-prescribed antibiotics from local pharmacies for the treatment of common cold. This data again highlights the use of life saving drugs for common viral infections. These antimicrobial resistant infections are a burden on one's national economy. For example, an increase in demand for hospitalization and a greater need of paramedic staff will increase cost and strain the country's economy. ${ }^{16} \mathrm{As}$ far as our public is concerned, they don't have sound knowledge about what antibiotics resistance truly is, so this factor further aggravates the problem. ${ }^{17}$

Behavior of medical students regarding completion of antibiotic course and self-medication: Regarding behavior, $14.5 \%(n=29)$ students from pre-clinical and $40.6 \%(n=52)$ from clinical professionals agreed to self-medicate themselves on antibiotics twice per annum. Self-medication reflects an increasing trend in Pakistan. Lack of proper guidelines and communication is the reason behind this. This per capita increase in antibiotics use is the major cause of antibiotics resistance. ${ }^{18}$ Another study conducted in North America also reported a $46 \%$ increase in antibiotics consumption. ${ }^{19}$ The excessive use of a broad-spectrum antibiotics also remains the most important reason behind this overuse. ${ }^{20}$

The Ethical Conundrum of sharing Antibiotics: Over the counter antibiotics and resistance are intertwined with major ethical principles. ${ }^{21}$ People in developing countries with their developing knowledge regarding usage of western medicine are associated with antibiotics sharing on a vast level. People prefer the symptomatic relief within a day rather than taking the full antibiotic course recommended by healthcare professionals. ${ }^{22}$ In this way, they are comprising their health autonomy without even knowing what that principle is. Inquiring from medical students, about this particular problem of sharing antibiotics with someone in their friends and family with similar symptoms as them, $16.5 \%(n=33)$ from pre-clinical and $41 \%(n=82)$ from clinical professionals agreed to share them. Ultimately the debate over this fact falls under the individual versus society effects. ${ }^{23}$

\section{CONCLUSION}

The number of bacteria resistant to everyday antibiotics will increase, leading to invalidation of current treatments leading to prolonged hospital stays, unaffordable medical costs, and increased mortality rate among society. This would be a burden on the world's healthcare and economy. The solution to this is following protocol when it comes to the use of antibiotics. Governmentally, laws should be implemented with the help of professional associations (WHO) and policy makers to increase regulation of antibiotics to prevent misuse by the public. Interventional strategies such as development of training modules in medical education curriculum and continuous medical education are needed towards bettering this situation 
will eventually contribute to the overall health and wellness of the population.

\section{LIMITATIONS}

This research was conducted only in one public sector medical college so its result can't be generalized. Abuse of intake of antibiotics causes multiple problems on a global scale.

\section{SUGGESTIONS / RECOMMENDATIONS}

Strong laws must be implemented to prevent the ever-growing unnecessary sale of OTC antibiotics especially in Pakistan. Moreover, the public needs to be aware of the consequences followed by over usage of these medicines which may lead to resistance, producing microbes that make them ineffective. Several awareness campaigns can play an important role in this regard. Since, resistance is not a new problem that affects healthcare and pharmaceutical facilities.

\section{CONFLICT OF INTEREST / DISCLOSURE}

None.

\section{ACKNOWLEDGEMENTS}

We take this opportunity to record our deep sense of gratitude to our worthy teacher, guide and supervisor Dr. Sumera Badar Ehsan, Assistant Professor, Department of Medical Education, FMU, Faisalabad, for her encouragement, useful suggestions and constructive criticisms in completion and presentation of this study.

\section{REFERENCES}

1. Antibiotics definition; The Editors of Encylclopaedia, July 11, 2019

2. AC Buke, S Ermertcan, M Hosgor-Limoncu, M Ciceklioglu, S Eren. Rational antibiotic use and academic staff. Int J Antimicrob Agents. 2003;21(1):63-6.

3. Misuse definition ; Merriam Webster Dictionary

4. Metlay JP, Stafford RS, Singer DE. National trends in the use of antibiotics by primary care physicians for adult patients with cough. Arch Intern Med. 1998;158(16):1813-8.

5. Donkor ES, Tetteh-Quarcoo PB, Nartey P, Agyeman IO. SelfMedication Practices with Antibiotics among Tertiary Level Students in Accra, Ghana: A Cross-Sectional Study. Int J Environ Res Public Health. 2012;9(10):3519-29.

6. Gyssens IC. Quality measures of antimicrobial drug use. Int J Antimicrob Agents. 2001;17(1):9-19.

7. O'Neill J. Tackling Drug-Resistant Infections Globally: Final Report and Recommendations. 2016. UK: HM Government and Welcome Trust; 2018.

8. "Antimicrobial resistance" World Health Organization page

9. Kang $\mathrm{Cl}$ and Song JH. Antimicrobial Resistance in Asia: Current Epidemiology and Clinical Implications. Infect Chemother. 2013;45(1):22-31.

10. Naveed S, Qamar F, Maqsood A, Ayub A, Kauser H, Malik H, Fatima $\mathrm{K}$ and Hameed $\mathrm{A}$. Prevalence and Consequences of Misuse of Antibiotics, Survey Based Study in Karachi. J Bioequiv Availab. 2015;7(5):202-4.

11. Atif M, Asghar S, Mushtaq I, et al. What drives inappropriate use of antibiotics? A mixed methods study from Bahawalpur, Pakistan. Infect Drug Resist. 2019;12:687-9.

12. Cooper RJ. Over-the-counter medicine abuse - a review of the literature. J Subst Use. 2013;18(2):82-107.

13. S KI, Chandy SJ, Jeyaseelan L, Kumar R, Suresh S. Antimicrobial prescription patterns for common acute infections in some rural and urban health facilities of India. Indian J Med Res. 2008;128(2):165-71.

14. Oli AN, Eze DE, Gugu TH, Ezeobi I, Maduagwu UN, Ihekwereme CP. Multi-antibiotic resistant-spectrum beta-lactamase producing bacteria pose a challenge to the effective treatment of wound and skin infections. Pan Afr Med J. 201730(27):66.

15. McDermott L, Leydon GM. Halls A the PIPS investigators, Qualitative interview study of antibiotics and self-management strategies for respiratory infections in primary care. BMJ. 2017;7(1):1-7.

16. "Antibiotic resistance strikes hardest at the poor"

17. "WHO's first global report on antibiotic resistance reveals serious, worldwide threat to public health" World Health Organization report

18. Ventola CL. The antibiotic resistance crisis: part 1: causes and threats. P T. 2015;40(4):277-83.

19. David M. Patrick, Marra F, Hutchinson J, Monnet DL, Helen Ng, William RB. Per Capita Antibiotic Consumption: How Does a North American Jurisdiction Compare with Europe?. Clin Infect Dis. 2004;39(1):11-7.

20. Walle-Hansen M, Høye S. Geographic Variation in Antibiotic Consumption-Is It Due to Doctors' Prescribing or Patients' Consulting? Antibiotics (Basel). 2018;7(1):26.

21. Parsonage B, Hagglund PK, Keogh L, Wheelhouse N, Brown RE, Dancer SJ. Control of Antimicrobial Resistance Requires an Ethical Approach. Front Microbiol. 2017;8:2124.

22. National Collaborating Centre for Women's and Children's Health (UK). Antibiotics for Early-Onset Neonatal Infection: Antibiotics for the Prevention and Treatment of Early-Onset Neonatal Infection. London: RCOG Press; 2012 Aug. (NICE Clinical Guidelines, No. 149.) 10, Duration of antibiotic treatment.

23. Malik, B., Bhattacharyya, S. Antibiotic drug-resistance as a complex system driven by socio-economic growth and antibiotic misuse. Sci Rep. 2019;9:9788.

\section{AUTHORSHIP CONTRIBUTION}

Mehr Muhammad Adeel Riaz

Rameen Shahid

Areeba Naeem

Sumera Badar Ehsan

Sajjad Ali

Mariam Saleem
Manuscript Writing and Data Analysis

Data Collection

Literature Review

Supervisor

References layout

Statistical Analysis 